\title{
A atuação de Antônio Luis Cavalcanti de Albuquerque de Barros Barreto na Reforma Sanitária da Bahia (1924-1930)
}

\author{
The Actuation of Antônio Luis Cavalcanti de Albuquerque \\ de Barros Barreto in the Sanitary Reform of Bahia (1924-1930)1
}

Ricardo dos Santos Batista*

Maria Elisa Lemos Nunes da Silva**

\section{RESUMo}

$\mathrm{O}$ artigo tem como objetivo analisar a trajetória profissional do médico Antônio Luis Cavalcanti de Albuquerque de Barros Barreto, ex-bolsista da Fundação Rockefeller e Inspetor do Departamento Nacional de Saúde Pública, na reforma sanitária ocorrida na Bahia, entre 1924 e 1930. Para a compreensão desse processo, são utilizados os Relatórios e o discurso de posse do médico na Subsecretaria de Saúde e Assistência Pública, o seu cartão de bolsista na Rockefeller, o memorial apresentado à Faculdade de Medicina da Bahia, os Archivos Paranaenses de Medicina e os Archivos Brasileiros de Medicina. A contextualização das fontes permitiu compreender que a atuação de Barros Barreto buscou alinhar as ações desenvolvidas no estado com os ideais do movimento sanitarista da segunda década do século XX e da Fundação Rockefeller.

Palavras-chave: Fundação Rockefeller; Reforma Sanitária da Bahia; formação profissional.

\section{Abstract}

This study aims to analyze the professional trajectory of Antônio Luis Cavalcanti de Albuquerque de Barros Barreto, former Fellow of the Rockefeller Foundation and Inspector of the National Department of Public Health, in the Health Reform in Bahia, between 1924 and 1930. To understand this process, Reports and the doctor's acceptance speech in the Sub-board of Health and Public Assistance, his card of Rockefeller, the memorial presented to the Faculty of Medicine of Bahia, the Archivos Paranaenses de Medicina and the Archivos Brasileiros de Medicina are used. From the contextualization of sources, it was understood that the role played by Barros Barreto was fundamental for the alignment of the actions developed in the state, with the influence of the health movement's ideals from the second decade of the twentieth century and of the Rockefeller Foundation.

Keywords: Rockefeller Foundation; Bahia Sanitary Reform; professional training.

\footnotetext{
* Universidade do Estado da Bahia (Uneb), Alagoinhas, BA, Brasil. kadobatista@hotmail.com <https:// orcid.org/0000-0002-7959-5929>

** Universidade do Estado da Bahia (Uneb), Alagoinhas, BA, Brasil. elisalemosmaria@gmail.com $<$ https://orcid.org/0000-0002-4502-4730>
} 
Estudos sobre trajetórias individuais vêm se ampliando cada vez mais no espaço acadêmico. Durante muito tempo esses trabalhos foram vistos como modelo de história tradicional, voltados para narrativas apologéticas. O retorno à biografia no âmbito da história não significou a retomada de um "gênero velho", mas acompanhou as reflexões teóricas e metodológicas da disciplina, como, por exemplo, a relação entre indivíduo e sociedade e as formas de narrativas do conhecimento histórico (Schmidt, 2000, p. 49, 51).

Pierre Bourdieu (2006, p. 183-185), em artigo publicado em 1986, chamou atenção para a necessidade de superar a visão do senso comum acerca da escrita de trajetórias de vida, realizada como a descrição de um trajeto unidirecional que tem começo, etapas e finalidade. Ela seria movida pelo intuito de dar um sentido e tornar lógica a história de uma personagem, em uma criação que não deixa de ser artificial. Essa concepção não estaria livre dos riscos de produzir uma ilusão retórica, uma representação comum da existência, que toda uma tradição literária não deixou de reforçar.

Ao se lançar na escrita biográfica, muitos autores constroem trajetórias lineares que privilegiam o sentido do "nome próprio", aquele a quem o historiador deseja seguir como uma identidade social coerente e durável, buscando garantir a identidade do indivíduo biológico em todos os campos possíveis, onde ele intervém como agente. Contudo, é necessário repensar as "histórias de vida" ou as "trajetórias" como uma série de posições sucessivamente ocupadas por um mesmo agente, num espaço que é ele próprio um devir, estando sujeito a incessantes transformações (Bourdieu, 2006, p. 189).

Algumas questões teóricas figuram como desafios aos historiadores dos estudos biográficos e de trajetórias. Segundo Benito Schmidt (2004, p. 22-23), destaca-se a necessidade de um diálogo micro-histórico, o que é possível a partir da redução da escala de observação, em uma análise microscópica, com um estudo intensivo do material documental e a compreensão da representatividade da personagem analisada. Por mais singular que seja um indivíduo, existem sempre pontos de contato entre suas vivências e concepções e as de seus contemporâneos, pois todos compartilham em maior ou menor grau determinados códigos culturais que permitem a convivência e a comunicação.

Contudo, deve-se ter o cuidado de não tentar explicar o indivíduo pelo contexto ou mesmo o contexto pelo indivíduo. Há de se perceber uma permanente tensão entre constrangimentos sociais e liberdades individuais, visto que as personagens históricas tiveram diante de si um futuro incerto e indeterminado no qual fizeram escolhas, num campo de possibilidades historicamente determinadas (Schmidt, 2004, p. 24). 
Entre as possibilidades dessa modalidade de escrita estão os estudos sobre trajetórias acadêmicas e profissionais (Ferreira, 1994; Maio, 1995; Paiva, 2006; Silva, 2013; Silva, 2014; Hochman; Lima, 2015; Batista, 2019a), que têm contribuído significativamente para a ampliação dos debates sobre o desenvolvimento das ciências e das políticas sanitárias no Brasil. Em sua maioria, dialogam com o conceito de campo científico, de Bourdieu, que é definido como um sistema de relações objetivas entre posições adquiridas em lutas anteriores, o espaço de jogo de uma luta concorrencial. Para o autor, o que está em jogo especificamente nessa luta é o monopólio da autoridade científica definida, a capacidade de falar e agir de maneira autorizada e com autoridade, socialmente outorgada a um agente determinado (Bourdieu, 1983, p. 123).

Nessa perspectiva, por exemplo, Marcos Maio (1995) analisa a trajetória do médico maranhense Raimundo Nina Rodrigues, desde a admissão na Faculdade de Medicina da Bahia até sua conversão definitiva à medicina legal com a ocupação da cátedra dessa disciplina, em 1895. O autor reconstituiu aspectos da medicina baiana entre o Império e o início da República, destacando o papel da Escola Tropicalista Baiana e da medicina experimental desenvolvida por ela, as inserções de Nina Rodrigues nesse movimento científico e sua adesão ao campo da Medicina Legal, revelando os conflitos de interesses presentes dentro de um mesmo grupo (Maio, 1995).

Em pesquisa sobre a trajetória do médico João Vicente Torres Homem, Luiz Otávio Ferreira (1994) discute a institucionalização da medicina experimental em oposição a uma forte tradição clínica. Contudo, para ele, é necessário conhecer as especificidades dessa última, não como obstáculo para o desenvolvimento da ciência, mas como uma tradição científica plenamente institucionalizada e portadora de padrões de formação intelectual, de carreira profissional e de produção de conhecimentos próprios a serem descritos e analisados mediante o estudo das trajetórias dos membros das elites médicas (Ferreira, 1994, p. 63-65).

E, entre muitos outros exemplos que se poderiam citar, André Felipe Cândido da Silva (2013) apresenta o conflituoso processo de escolhas do médico Henrique da Rocha Lima, o qual determinou a sua identidade científica: a opção pela medicina experimental e a identificação com ciência e cultura germânicas. Além disso, discute como a tensão das suas escolhas refletia problemáticas compartilhadas por seus contemporâneos, além de iluminar processos mais amplos sobre as raízes da medicina experimental.

Com base nesse campo historiográfico específico, este artigo tem o objetivo de analisar parte da atuação de Antônio Luis Cavalcanti de Albuquerque 
de Barros Barreto (1892-1954) na Reforma Sanitária da Bahia, de 1924 a $1930 .^{2}$ Ao acompanhar esse aspecto da sua trajetória, relacionando o individual ao coletivo, foi possível observar questões voltadas para as políticas de saúde em âmbito estadual e nacional. Entre as ações que promoveu, destaca-se o estímulo à profissionalização dos agentes de saúde que ocupavam cargos de liderança no estado e foram enviados a instituições nacionais e de outros países para estudar saúde pública, higiene escolar e higiene industrial, entre outros temas. Além disso, a Educação Sanitária foi considerada o principal meio de evitar a proliferação de doenças.

O corpus documental utilizado para a análise é constituído por relatórios produzidos pelo médico, os quais detalham as principais mudanças ocorridas na organização sanitária do estado sob o seu comando; o discurso de inauguração da Subsecretaria de Saúde e Assistência Pública da Bahia; o memorial apresentado à Faculdade de Medicina da Bahia para concorrer à vaga de professor de Parasitologia; os Archivos Paranaenses de Medicina, os Archivos Brasileiros de Medicina e cartões de bolsistas da Fundação Rockefeller. Trata-se de uma documentação que precisa ser entendida na sua condição de produção. Parte dela foi elaborada pelo sanitarista, sendo instrumento de registro e de divulgação das ações que empreendeu.

\section{BARROS BARRETO: UM SANITARISTA BRASILEIRO, BOLSISTA DA FUNDAÇÃo ROCKEFELLER}

Antônio Luis Cavalcanti de Albuquerque de Barros Barreto (1892-1954) nasceu e cresceu nas cercanias de Recife, em Pernambuco, e se mudou para o Rio de Janeiro em 1910, quando se matriculou na Faculdade de Medicina do Rio de Janeiro. Em 1913, iniciou o Curso de Aplicação do Instituto Oswaldo Cruz (IOC), onde desenvolveu trabalhos no campo da investigação experimental. Esse percurso formativo contribuiu para a construção de habilidades intelectuais que dialogavam com a bacteriologia, com a medicina tropical e com os ideais do movimento sanitarista da década de $1910 .{ }^{3}$ Foi aluno de médicos como Carlos Chagas, que ganhava notoriedade pela descoberta científica que levou seu nome, e de Adolpho Lutz, e foi orientado por Oswaldo Cruz a se aprofundar nos estudos sobre helmintologia (Barros Barreto, 1918, p. 9-13). Tornou-se Assistente do IOC e, posteriormente, Inspetor do Departamento Nacional de Saúde Pública (DNSP), criado em 1920. Desde cedo também estabeleceu relação com o projeto da Fundação Rockefeller no Brasil (Batista, 2019a). 
A Fundação Rockefeller se inseriu no país no contexto do sanitarismo da década de 1910, como parte da sua expansão global. Criada em 1913 por John D. Rockefeller, compreendia a doença como principal fonte da pobreza e defendia que a melhoria da saúde das populações era o meio mais eficaz de eliminar problemas econômicos e sociais. A Fundação financiou campanhas de erradicação de enfermidades e de formação de profissionais da saúde, e disseminou uma medicina preventiva com métodos próprios (cf. Palmer, 2015). A Instituição norte-americana também promoveu o envio de bolsistas para os Estados Unidos, a fim de convertê-los à "ciência da saúde pública norte-americana" e transformá-los em representantes desse saber em seu país de origem (Cueto, 1994, p. xi; Löwy, 2006, p. 139).

Graças ao desempenho de destaque no IOC, Barros Barreto foi um dos jovens brasileiros escolhidos para estudar no exterior, financiado pela Fundação Rockefeller. Em 11 de setembro de 1921, com 29 anos de idade, ele se estabeleceu em Baltimore para realizar o curso de Higiene e Saúde Pública (RAC, Box 8, p. 1-2). Estudou até o final de junho de 1922 com o Dr. Baetjer, do Hospital Johns Hopkins, e em julho se dirigiu a Nova York. Recebeu cartas de apresentação para o Hospital Montefiore, para o Blythewood Sanitarium Greenwich e para o Hospital Naval, no Brooklyn. Como também tinha interesse pela Higiene Industrial, visitou instituições como o Memorial Hospital, a American Telephone e Telegraph e a N. Y. State Society for Promotion of Occupational Therapy. Solicitou a expansão da bolsa por mais um ano, para estudar na França, o que não lhe foi permitido. Mesmo sem a continuidade do financiamento, seguiu para a Europa e frequentou instituições de ensino, pesquisa e assistência à saúde. Diplomou-se em Dermatologia e Venereologia pela Faculdade de Medicina de Paris (Barros Barreto, 1935, p. 4).

O médico retornou ao Brasil com o objetivo de liderar um projeto de saúde, conforme propunha a Fundação Rockefeller para os seus bolsistas. Segundo Korndörfer (2013, p. 238-239), eles deveriam se especializar em áreas que fossem consideradas importantes e, posteriormente, ocupar uma posição de suficiente autoridade e influência para justificar os gastos da Rockefeller com a sua formação. Outros sanitaristas brasileiros financiados pela instituição, que estudaram Saúde Pública em Baltimore, já haviam ocupado cargos públicos de destaque na liderança sanitária em outros estados brasileiros. Segundo Cristina de Campos (2013, p. 37), os dois primeiros paulistas contemplados com bolsas da Fundação Rockefeller foram Francisco Borges Vieira e Geraldo Horácio de Paula Souza, que ocupavam os cargos de auxiliares da Cadeira de Higiene na Faculdade de Medicina de São Paulo. 
Nomeado para o Saneamento Rural do Paraná em 18 de março de 1924, Barros Barreto começou a executar um plano sanitário e se tornou redator-chefe dos Archivos Paranaenses de Medicina. No período em que atuou naquele estado, afirmou ter visitado postos do Serviço de Profilaxia Rural, exceto os de Foz de Iguaçu e os situados na zona Norte do estado, como Jacarezinho (e subpostos de Santo Antônio da Platina) e Thomazina (subpostos de Colônia Mineira e S. Jeronymo), que não foram percorridos por conta do acúmulo de trabalho na sede do serviço em Curitiba (Barros Barreto, 1924). Sua presença no estado sulista foi ressaltada no noticiário do periódico médico, o qual também lhe desejava tempo suficiente para realizar o programa que havia anunciado, no novo estado para o qual seria transferido: a Bahia (Barros Barreto, 1924, p. 110).

A análise do trabalho que Barros Barreto desenvolveu na saúde pública da Bahia, entre 1924 e 1930, indica que o projeto interrompido no Paraná foi posto em prática naquele estado (cf. Batista, 2016; Batista, 2017a; Batista, 2017b; Silva, 2018). É possível que por ser funcionário do Governo Federal, sem esposa nem filhos, Barros Barreto tenha tido facilidade em permanecer no exterior por 2 anos (um deles, nos Estados Unidos da América, como bolsista da Fundação Rockefeller, e o outro na Europa). Ao retornar ao Brasil, pôde ainda residir em alguns estados para atender às diferentes demandas do DNSP. Esse percurso se diferencia, por exemplo, daquele realizado por Fernando de Freitas e Castro. O médico gaúcho, ligado à Diretoria de Higiene, era professor substituto de Higiene da Faculdade de Medicina do Rio Grande do Sul e viajou ao exterior para se profissionalizar somente após firmar-se a cooperação entre o seu estado e a Rockefeller, devendo, após a formação, retornar para ocupar os mesmos cargos (Korndörfer, 2013, p. 245).

Barros Barreto chegou à Bahia em 1924, num momento de disputa entre os médicos do estado e os profissionais da Fundação Rockefeller quanto à melhor forma de enfrentamento da febre amarela. As divergências tinham levado, 2 anos antes, o diretor do Serviço de Profilaxia Rural na Bahia, Sebastião Barroso, a pedir demissão do seu cargo, em um ato público realizado em frente à Sociedade Médica. Ele acusou a Fundação de exceder os limites da sua autoridade e assumir o controle total do programa; dispensar o método da fumigação, que havia sido utilizado com êxito por Oswaldo Cruz no Rio de Janeiro em 1909, e inserir peixes de larvófagos ou uma camada de óleo em depósitos de água potável em cidades do interior, onde havia escassez de água (Benchimol, 2011, p. 113; Pontes, 2007, p. 95). 
A vacância da chefia do Serviço de Profilaxia Rural na Bahia, com a saída de Barroso, colocava a necessidade de preenchê-la com um profissional que desenvolvesse o trabalho sem maiores conflitos, para que as ações de combate à febre amarela pudessem avançar de forma satisfatória. Barros Barreto foi considerado uma alternativa para minimizar os efeitos da crise e levar adiante o processo de Reforma Sanitária na Bahia. O ex-bolsista precisava conciliar, naquele momento, os ideais do sanitarismo brasileiro da década de $1910 \mathrm{com}$ as concepções médicas da Fundação Rockefeller.

\section{Profissionalização técnica e COMbate A DOENÇAS NA BAHIA}

Quando Barros Barreto assumiu a chefia dos serviços de saúde em âmbito estadual, durante o governo de Francisco Marques de Góes Calmon (19241928), estava em curso a Reforma Sanitária propiciada pela criação do DNSP, em 1920. Esse órgão, subordinado ao Ministério da Justiça e Negócios Interiores, tinha objetivo intervencionista estatal de cunho nacional, respeitadas as perspectivas federalistas da Constituição de 1891.

Batista (2017a, p. 157) afirma que o médico sofreu ataques constantes no jornal soteropolitano Diário de Notícias, em uma série de textos que cobrava eficiência do Departamento Nacional. Os conflitos podem ser observados em sua própria fala:

não me atemorizei com a atitude de reserva com que fui recebido, pelos médicos baianos, sobretudo por elementos do corpo docente da mais antiga faculdade de medicina do país, da qual era figura de escol o Diretor de Higiene demissionário, nem tão pouco me intimidei com os comentários da imprensa local, que logo de início entrou a criticar com mais ampla liberdade todos os meus atos. (Barros Barreto, 1931, p. 1)

As críticas devem também ser observadas à luz das disputas políticas locais. O processo de reforma sanitária na Bahia, embora tivesse sido ampliado no governo de Góes Calmon, fora iniciado em 1921, durante o governo de José Joaquim Seabra (1920-1924), ocasião em que se firmou um acordo com o governo federal para a realização de serviços de Saneamento Rural, de combate à sífilis e às doenças venéreas, de luta contra a tuberculose e de higiene infantil (Batista, 2017a, p. 27, 71). Seabra e Góes Calmon eram opositores políticos. ${ }^{4}$ $\mathrm{Na}$ gestão sanitária de Barros Barreto as políticas do estado se equipararam cada vez mais à proposta do Governo Federal com a criação da Subsecretaria 
de Saúde e Assistência Pública e do Código Sanitário da Bahia, em 1925 (Batista, 2017a, p. 71).

Cabe lembrar que a ideia de criação de um Código Sanitário que reunisse todas as disposições elaboradas pelo Conselho Geral Sanitário remontava à Lei n. 213, de 25 de agosto de 1897, promulgada no governo de Luiz Vianna (18961900). Barros Barreto reconhecia a antiguidade dessa discussão, mas registrava que ela não havia saído do papel. No entanto, identificava os avanços alcançados por seus antecessores no que definiu como os pontos positivos da lei: a obrigatoriedade da vacinação antivariólica para crianças no período de 6 meses após o nascimento, prazo que em épocas epidêmicas devia ser reduzido aos 3 meses; a notificação compulsória, estabelecida pela primeira vez na Bahia nos casos de moléstias transmissíveis capazes de assumir caráter epidêmico e cuja lista cabia ao Conselho de Saúde Pública organizar; a criação de postos de desinfecção de passageiros e bagagens; a divisão da cidade em distritos sanitários e a determinação de se realizar, com urgência, um recenseamento da população pela Seção de Estatística Geral do Estado (Barros Barreto, 1928, p. 12).

Christiane Souza (2009, p. 63-68) em estudo acerca da gripe espanhola que atingiu o estado da Bahia em 1918, considera que, desde o século XIX, houve um esforço, por parte dos governos instituídos, em montar uma estrutura sanitária para atender à população. Esse esforço, por sua vez, esteve longe de dar conta dos problemas de saúde vivenciados, principalmente pelos setores menos favorecidos.

No discurso de instalação da Subsecretaria de Saúde e Assistência Pública, ocorrido em 1925, por sua vez, o médico apresentou posicionamento acerca das concepções de saúde que orientavam seu trabalho, especialmente na reorganização administrativa e na criação do Código Sanitário da Bahia:

Certo não faltará quem nos venha dizer que a nova organização sanitária da Bahia não satisfaz o tipo ideal de certas modalidades norte-americanas. Nem esse foi o nosso objetivo, nem este o padrão mais aconselhável. Deixamos falar a vontade os que fazem higiene no espaço, os que alardeiam uma cultura técnica filha exclusivamente de leituras mal dirigidas de periódicos estadunidenses, os que nunca tiveram o ensejo de conhecer de perto as inúmeras dificuldades deparadas na execução de medidas que visem a defesa da saúde coletiva, os que transportados nas asas largas da fantasia e comodamente instalados em confortáveis gabinetes, doutrinam sobre ciência sanitária, sem atentarem na exequibilidade das providencias que preconizam. (Barros Barreto, 1925, p. 2-3) 
A fala de Barros Barreto apresenta uma crítica a outros profissionais da medicina, que seguiam a tradição clínica e não desenvolviam investigações in loco sobre as condições de saúde. Como poucos pesquisadores brasileiros daquele período, o médico conhecia de perto a organização sanitária dos Estados Unidos e reiterou as dificuldades encontradas na implementação de medidas para a defesa da saúde pública. Ao mesmo tempo, também informou sobre a sua filiação ao IOC:

Filho da nova geração de sanitaristas brasileiros, educado na escola de Oswaldo Cruz cedo aprendia não temer responsabilidades, nem me intimidar com os momentos difíceis da profissão que abracei [...] O grito doloroso de Miguel Pereira - o Brasil é um vasto hospital -, desprezadas as condições do momento em que foi lançado, perdoado o entusiasmo quase apostolar que o envolve, reduzindo as suas justas proporções, nem por isso deixa de ser menos verdadeiro. E, quanto mais não fosse, serviu para despertar a consciência brasileira chamando a atenção dos dirigentes de nosso povo para a vastidão de problemas sanitários comprometendo seriamente o porvir de uma nacionalidade. (Barros Barreto, 1925, p. 3)

O médico destacou a importância do discurso proferido por Miguel Pereira em 1916, demonstrou preocupação com a população sertaneja e se declarou incapaz de punir o Jeca, "representante do povo brasileiro", pela condição de doença em que se encontrava. A referência a Jeca Tatu, personagem criada por Monteiro Lobato, estava relacionada às mudanças na compreensão sobre a condição de saúde dos brasileiros após a publicação do relatório dos médicos Belisário Penna e Arthur Neiva, os quais realizaram viagens a regiões distantes do Brasil, organizadas pelo Instituto Oswaldo Cruz, com vistas a conhecer as condições sanitárias da população dos sertões. Lima e Hochman (1996, p. 31) analisam a importância do movimento sanitarista para a reconstrução da identidade nacional a partir do elemento distintivo da condição de ser brasileiro e afirmam que escritores como Monteiro Lobato foram influenciados pelo texto dos cientistas de Manguinhos. Em uma série de artigos publicados no jornal O Estado de S. Paulo, Lobato esboçou uma nova imagem do Jeca, não mais considerado como naturalmente indolente, mas assim mantido em razão das doenças que o afligiam. Uma vez tratado, ele se tornaria a redenção do homem do interior e do próprio Brasil.

Barros Barreto se posicionava sobre os processos formativos que compuseram a sua trajetória e indicava os elementos que considerava necessários para o desenvolvimento do país. Ele conseguia refletir sobre as diretrizes difundidas 
pelo movimento sanitarista e pela Rockefeller e tentava adequá-las às condições possíveis de serem desenvolvidas naquela realidade. Não desejava apenas denunciar o abandono da população pobre e residente distante dos grandes centros urbanos, mas alcançar os sertões para então saneá-los. Assim, reconhecia ser preciso observar a vida dos sertanejos e a necessidade de expansão do Estado. Segundo Hochman (1993, p. 53), “o saneamento dos sertões” não era apenas figura retórica de um movimento que buscava uma identidade nacional, mas um projeto, um processo de construção do poder público e, por meio desses, de integração territorial.

Em 1927, a Subsecretaria de Saúde e Assistência Pública da Bahia foi transformada em Secretaria de Saúde e Assistência Pública e continuou sob a direção de Barros Barreto. É possível observar que, ao longo da Reforma Sanitária na Bahia, ocorreu um redirecionamento das orientações técnicas, articuladas internamente e alinhadas ao projeto nacional. Segundo o médico, havia até aquele momento três repartições de higiene na Bahia, cujas relações nem sempre primavam pela boa harmonia e a orientação, não raro, "se debatia entre pontos de vista doutrinários, às vezes completamente antagônicos": a Diretoria Geral de Saúde Pública do estado, a Diretoria de Higiene e Assistência Municipal, e o Serviço Federal de Saneamento Rural, Profilaxia da Lepra e Doenças Venéreas, Higiene Infantil e Luta Antituberculose, incumbido também da fiscalização dos trabalhos da Comissão de Febre Amarela, executados pela Fundação Rockefeller (Barros Barreto, 1928, p. 23).

A análise de Pontes (2007, p. 120) reitera essas informações, mesmo que a ideia sobre um antagonismo entre as correntes da medicina precise ser relativizada. ${ }^{5}$ Segundo o autor, quando da nomeação de Barros Barreto para o Serviço Sanitário Federal na Bahia, havia um conflito entre duas visões diferentes de medicina: enquanto o médico do Serviço Sanitário Estadual, Aristides Novis, adotava uma perspectiva da "medicina urbana", com isolamento dos doentes, fechamento de escolas e internatos e desinfecção de casas ao longo da epidemia de febre tifoide, o médico Genésio Pacheco, pesquisador do IOC contratado pelo DNSP para investigar as causas da doença, agia à luz da medicina investigativa, de base experimental e bacteriológica.

A "unidade da direção", proposta por Barros Barreto, foi acompanhada de outra característica que favoreceu o processo de reforma da saúde na Bahia: a completa autonomia técnica, administrativa e financeira da Subsecretaria de Saúde e Assistência Pública. O novo órgão sanitário não dependia mais da Secretaria do Interior, Justiça e Instrução Pública, ficava subordinado diretamente ao governador do Estado. O médico pernambucano propunha um programa 
sanitário baseado em pressupostos bacteriológicos. Chegado recentemente a um estado no qual não havia nascido, em meio a embates políticos e médicos, descaracterizava outras perspectivas de atuação médica como forma de se impor profissionalmente e obter legitimidade no campo científico da Bahia.

A confluência entre a sua formação em Manguinhos e na Fundação Rockefeller, o lugar de chefia sanitária nas três esferas de governo (municipal, estadual e federal) e as boas relações com Góes Calmon, inclusive pela condição de genro, contribuíram para assegurar a autonomia necessária para a implantação, no estado, das políticas de saúde que defendia.

Na elaboração do Código Sanitário baiano, Barros Barreto regulamentou a formação técnica do pessoal da saúde com princípios apreendidos nos estudos desenvolvidos nos Estados Unidos. Lá ele conheceu códigos sanitários de diversos estados norte-americanos (Barros Barreto, 1923a, p. 1037). O artigo $8^{\circ}$ da Lei 1.811, de 29 de julho de 1925, determinava cuidado com a especialização dos funcionários e concedia ao governo o direito de enviá-los para aperfeiçoarem conhecimentos no IOC do Rio de Janeiro, nos Cursos de Saúde Pública da Universidade da Capital Federal e em instituições congêneres estrangeiras (Bahia, 1925, p. 9).

O médico compreendia a importância da profissionalização técnica em centros de pesquisa nacionais e internacionais especializados em conhecimentos como higiene industrial, higiene infantil, saúde pública e enfermagem, para fortalecer o desempenho dos agentes que participariam da implementação de políticas públicas na Bahia. Ao fazer um balanço sobre os 6 anos de administração sanitária sob o seu comando (1924-1930), informou ter promovido cerca de 40 viagens de estudos para os funcionários do quadro da saúde: sete ao exterior, e as demais aos serviços de higiene nacionais e a congressos científicos:

À América do Norte foram enviados dois técnicos: um para estudar Anatomia patológica e questões de laboratório concernentes à saúde pública, inclusive preparo de soro e vacinas; outro realizou o curso completo de biometria e estatística vital na Johns Hopkins University. Cinco viagens foram concedidas a médicos para visitarem as organizações sanitárias europeias. A chefe do serviço de "visitadoras" realizou no Rio de Janeiro, o curso completo da Escola de Enfermeiras do Departamento Nacional de Saúde Pública. Funcionários médicos efetuaram com real proveito os cursos completos de Malariologia e de Saúde Pública, na Capital do País. Outros permaneceram em demorado estágio nos serviços sanitários da capital da República, de S. Paulo e de Pernambuco. Aos congressos científicos onde se ventilaram assuntos de saúde pública, sempre esteve a Bahia, representa- 
da por técnicos de sua repartição de higiene, trazendo-lhes o fruto de sua experiência e de seu cabedal cientifico, em cerca de trinta memorias originais. (Barros Barreto, 1931, p. 16-17)

Em menos de 3 anos, a Subsecretaria enviou membros do seu quadro de pessoal à América do Norte, França, Alemanha, Suíça, Rio de Janeiro, São Paulo, Argentina e Uruguai, conforme se observa no Quadro 1:

Quadro 1 - Quadro de profissionais que se aperfeiçoaram fora do estado.

\begin{tabular}{|l|l|l|l|}
\hline & Nome & Destino & Objetivo da Viagem \\
\hline 1 & Dr. Eduardo de Araújo & América do Norte & $\begin{array}{l}\text { Laboratório de Saúde } \\
\text { Pública }\end{array}$ \\
\hline 2 & $\begin{array}{l}\text { Dr. Álvaro Franca } \\
\text { Rocha }\end{array}$ & França e Alemanha & Higiene Infantil \\
\hline 3 & Dr. Colombo Spínola & França, Alemanha e Suíça & Higiene Escolar \\
\hline 4 & Dr. Octavio Torres & América do Norte & $\begin{array}{l}\text { Laboratório } \\
\text { de Saúde Pública }\end{array}$ \\
\hline 5 & Dr. Álvaro Garcia Rosa & Rio de Janeiro & Curso de Malariologia \\
\hline 6 & Dr. José Farias Góes & Rio de Janeiro & $\begin{array}{l}\text { Curso do Instituto } \\
\text { Manguinhos }\end{array}$ \\
\hline 7 & Dr. Perry Guimarães & Rio de Janeiro e São Paulo & $\begin{array}{l}\text { Fiscalização de } \\
\text { Gêneros Alimentícios }\end{array}$ \\
\hline 8 & Dr. Dionísio Pereira & Rio de Janeiro e São Paulo & Centros de Saúde \\
\hline 9 & Dr. Murilo Celestino & $\begin{array}{l}\text { Argentina, Uruguai, } \\
\text { Rio de Janeiro e São Paulo }\end{array}$ & $\begin{array}{l}\text { Assistência } \\
\text { a Alienados }\end{array}$ \\
\hline 10 & Dr. Colombo Spínola & Rio de Janeiro e São Paulo & Higiene Escolar \\
\hline 11 & Dr. Guilherme Ramos & Rio de Janeiro & Curso de Saúde Pública \\
\hline 12 & Dr. Álvaro Garcia Rosa & Rio de Janeiro & Curso de Saúde Pública \\
\hline & $\begin{array}{l}\text { Dr. Martagão Gesteira, } \\
\text { Dr. Alfredo Britto, } \\
\text { Dr. Octavio Torres, } \\
\text { Dr. F. Magalhães Neto, } \\
\text { Dr. José Faria Góes, } \\
\text { Dr. Álvaro Garcia Rosa }\end{array}$ & São Paulo & $\begin{array}{l}\text { Curso de Enfermeiras } \\
\text { do DNSP }\end{array}$ \\
\hline 14 & $\begin{array}{l}\text { Enfermeira Estefânia } \\
\text { Barros }\end{array}$ & Rio de Janeiro & $\begin{array}{l}\text { Curso de Enfermeiras } \\
\text { do DNSP }\end{array}$ \\
\hline 15 & $\begin{array}{l}\text { Enfermeira Aurélia } \\
\text { Pitanga }\end{array}$ & Rio de Janeiro & \begin{tabular}{l} 
de Higienes \\
\hline
\end{tabular} \\
\hline
\end{tabular}

Fonte: Elaborado com base em Barros Barreto, 1928, p. 26. 
Os médicos Guilherme Ramos e Álvaro Garcia, por exemplo, frequentaram o Curso de Saúde Pública no Rio de Janeiro, ao passo que, no ano de 1928, também seriam enviados os doutores Exupério Braga e Guilhermino Milton da Silveira (Barros Barreto, 1928, p. 27). Segundo Castro Santos e Faria (2006, p. 292), o movimento em prol da profissionalização sanitária deu origem a propostas e à criação de escolas e serviços especializados, o que incluiu o ensino de Saúde Pública. Os autores apontam a experiência do do Instituto de Higiene de São Paulo (IHSP), embrião da atual Universidade de São Paulo (USP), como pioneiro na formação em Higiene no Brasil. A instituição foi criada com base nas diretrizes da Fundação Rockefeller, pautada na formação de sanitaristas que alargaram os caminhos para o surgimento de um novo modelo de atuação, sustentado na educação sanitária, na prevenção de doenças e na formação de recursos humanos.

No Rio de Janeiro, o Curso Especial de Higiene e Saúde Pública foi iniciado em 1926, com o objetivo de preparar médicos para o exercício da profissão sanitária, o que forneceu, ao recém-criado DNSP, pessoal especializado para o desempenho de cargos técnicos. Carlos Chagas solicitou à Fundação Rockefeller a vinda ao Brasil de dois de seus pesquisadores da área de epidemiologia e administração sanitária, que estiveram na inauguração do curso. Na parceria entre sanitaristas norte-americanos e de Manguinhos, os padrões e métodos da Rockefeller influenciaram e estimularam pesquisadores e sanitaristas brasileiros, mesmo que isso não significasse uma condição de recepção passiva. Embora fosse grande a influência europeia, o campo da saúde pública esteve desde muito cedo sob influência da comunidade científica norte-americana, em particular da nova geração da Johns Hopkins University (Castro Santos; Faria, 2006, p. 293-298).

Antônio de Barros Barreto foi um dos integrantes dessa nova geração. Durante a sua gestão, enviou médicos baianos aos Estados Unidos, como Eduardo de Araújo e Enoch Torres. Anteriormente à sua chegada haviam viajado médicos como José da Costa Pinto, Euvaldo Diniz Gonçalves e Octavio Torres, professores da Faculdade de Medicina da Bahia. Este último dirigia o Laboratório de Profilaxia da Diretoria de Saneamento Rural, inicialmente implantado no Posto de Saúde Pacífico Pereira, na rua das Sete Portas, em Salvador, mas transferido para as dependências da seção antirrábica do Instituto Oswaldo Cruz da Bahia (IOC-Ba), no bairro do Canela. Octávio Torres visitou o Laboratório de Saúde Pública norte-americano, entre setembro de 1924 e dezembro de 1925 (RAC, Box 8). Ele foi substituído pelo irmão, o médico Enoch Torres, também enviado à América do Norte, em 1929, para estudos de 
Estatística Vital e Biometria na Escola de Saúde Pública de Baltimore (Torres, 1927, p. 1-2). É importante destacar como os integrantes desse processo formavam uma restrita elite médica, que também envolvia laços familiares.

Barros Barreto destacou ainda a necessidade de contratar enfermeiras sanitárias. De acordo com as políticas propostas no regulamento do DNSP, elas desempenharam papel fundamental no combate a inúmeras doenças, como a sífilis e a tuberculose. Como não havia profissionais com a formação exigida, realizou-se em Salvador um curso de "visitadoras de higiene", no qual se inscreveram 35 alunas maiores de 21 anos, diplomadas pela Escola Normal da Capital, portadoras do título de "Bacharel em Ciências e Letras" pelo Ginásio da Bahia. A equipe de professores do curso de visitadoras baianas era formada por médicos da repartição sanitária do estado e habilitou 22 profissionais, após 4 meses de formação (Barros Barreto, 1928, p. 27-28).

Em análise sobre enfermeiras da saúde pública e educadoras sanitárias em São Paulo, Lina Faria (2006, p. 187) mostrou que, no conjunto de formação do campo das educadoras, as professoras primárias foram consideradas importantes aliadas na obra de divulgação das noções de higiene. Com as ideologias de construção nacional e a ocorrência de doenças endêmicas e epidêmicas, foram criadas novas oportunidades para as mulheres em um constante processo de feminização da enfermagem. Nas justificativas para a escolha das normalistas é recorrente a afirmação de que não havia enfermeiras formadas, caso também observado em Salvador. As professoras atuaram como visitadoras nos serviços estaduais até serem substituídas, gradativamente, por profissionais com formação e treinamento em saúde pública (Faria, 2006, p. 180).

Em relação ao Rio de Janeiro, Martha Cristina Nunes Moreira discute a criação de uma identidade profissional das enfermeiras, na tentativa de superar o perfil das visitadoras. A perspectiva de uma carreira construída para profissionais da enfermagem havia ganhado destaque a partir de 1922, quando foi criado o Serviço de Enfermeiras do DNSP, e em 1923, com a fundação da Escola de Enfermeiras do DNSP, denominada, em 1926, "Escola de Enfermeiras D. Anna Nery". Entre os atores que se destacaram nesse processo de instituição da enfermagem profissional no Brasil, estavam os médicos do DNSP, as enfermeiras norte-americanas enviadas pela Rockefeller e os visitadores de enfermagem (Moreira, 1999).

Barros Barreto afirmou que, em 1927, as enfermeiras sanitárias da Bahia, com instrução técnica especializada, dirigidas por uma profissional, auxiliaram a autoridade de Higiene no isolamento domiciliário dos doentes, nos estabelecimentos nosocomiais pertencentes à saúde pública, nos dispensários de 
tuberculose e de doenças venéreas e nos serviços de higiene infantil e escolar, realizando sobretudo a educação sanitária (Barros Barreto, 1928, p. 34).

Destaca-se que além da atualização técnica de profissionais da saúde em instituições nacionais e internacionais, a Lei de 1925 permitia, em seu artigo 7, a contratação de profissionais de outros estados para atuar na Bahia (Bahia, 1925, p. 9). Esse foi o caso do médico Ernane Agrícola, do Serviço Sanitário de Minas Gerais, técnico especialista em problemas de organização de Postos Municipais de Higiene, e de Carlos Burle de Figueiredo, que havia desempenhado papel importante nas ações da Fundação Rockefeller, no Rio de Janeiro (Barros Barreto, 1928, p. 27). Entre elas, a condução de conferências e propagandas e a troca de medicamentos por amostras fecais (como parte do método intensivo de erradicação da ancilostomíase), quando Olympio da Fonseca Filho deixou a central instalada pela Instituição em Rio Bonito (Batista, 2019a).

Assim, é possível afirmar que a partir de 1925 a Bahia investiu num processo de profissionalização técnica que seguia um duplo movimento, do interior para o exterior e do exterior para o interior, simultaneamente. Os profissionais se atualizavam em instituições de outros estados e países, retornavam e difundiam seus conhecimentos na multiplicação de outros agentes, enquanto atores de outros estados se inseriam na Bahia e contribuíam para uma formação local.

Entre as ações desenvolvidas pelos funcionários da saúde desde que se iniciou a administração de Barros Barreto, destaca-se a tentativa de melhorar as condições da vacina antivariólica, preparada pelo IOC-Ba, no intuito de se aparelhar para uma campanha intensa de proteção contra o terrível morbus. Era sua expectativa transformar o IOC-Ba em centro produtor de vacinas, dos mais variados, com a atuação dos bolsistas que enviou aos Estados Unidos.

Também foram desenvolvidas ações para o combate às grandes endemias como helmintoses, paludismo, leishmaniose, sífilis e doenças venéreas. Em parceria com o DNSP, houve investimento em ações voltadas para a profilaxia dessas doenças. O número de Postos de Saneamento Rural e dispensários antivenéreos que, em 1923, era de dez e seis, respectivamente, aumentou para 18 e 26, no fim de 1927. Até esse ano, foram tratadas 257.537 pessoas contra helmintoses, com 414.641 medicações aplicadas. Administraram-se 123.354 comprimidos de quinino, correspondentes a 61.677 gramas de alcaloides específicos para a malária. Passaram pelos dispensários de sífilis e doenças venéreas 327.004 enfermos, nos quais foram aplicadas 377.190 injeções. Distribuíram-se 42.130 folhetos de propaganda sanitária e foram efetuados no Laboratório Central do Serviço de Saneamento Rural da Capital 30.584 
exames, dos quais 20.789 de Wassermann para pesquisar possíveis casos de sífilis (Barros Barreto, 1928, p. 31).

Além de todos esses esforços em relação ao combate a doenças, foram realizadas obras para drenagem de águas onde proliferavam mosquitos. Destacam-se os trabalhos no centro urbano de Salvador (Ondina, Camarão e Areia Prata) (Figura 1), onde foram criadas galerias de concreto armado e valas capeadas de cimento. No interior do estado foram construídos vários canais simples, não protegidos de revestimento algum, mas atentos aos métodos para a profilaxia da malária (Barros Barreto, 1928, p. 31).

Figura 1 - Saneamento das baixadas de Ondina, Camarão e Areia Preta, Salvador, BA.

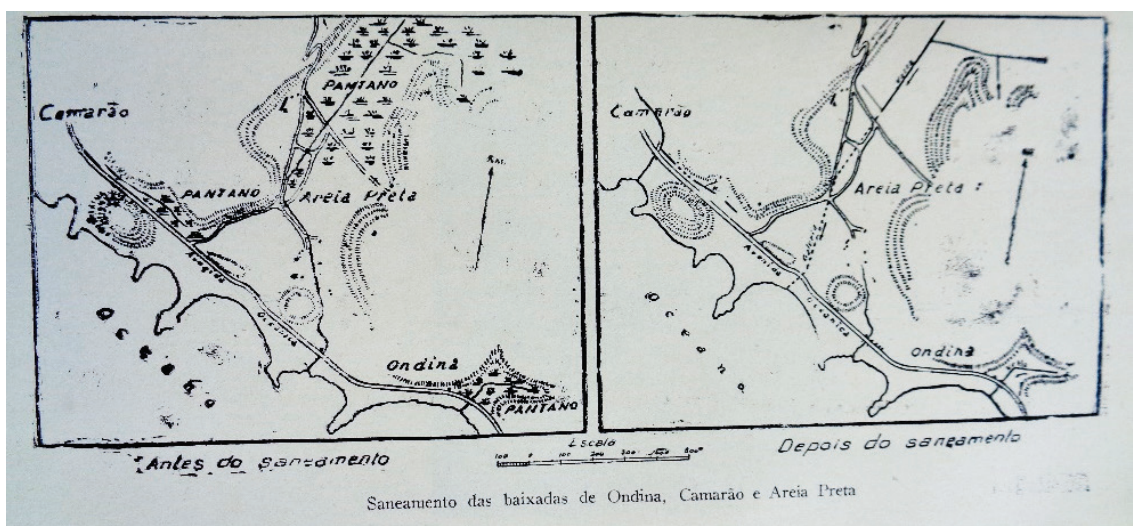

Fonte: Barros Barreto, 1928.

\section{O INVESTIMENTO EM EDUCAÇÃO E PROPAGANDA SANITÁRIAS}

Para Barros Barreto, a aplicação de medidas necessárias à defesa da saúde pública abrangia: "a legislação", que consistia no estabelecimento de normas que obrigassem o indivíduo a tomar as precauções vantajosas para a saúde geral; "a administração", método pelo qual o higienista tomaria as providências que visassem o benefício da coletividade, e "a educação", processo pelo qual o encarregado de zelar pela saúde do povo procuraria interessar o indivíduo no movimento em prol da saúde pública, instruindo-o para convencê-lo das vantagens da adoção das medidas aconselhadas e obrigá-lo a auxiliar a atividade sanitária na execução dessas providências. No ano de 1923, Barros Barreto já havia publicado, nos Archivos Brasileiros de Medicina, artigo no 
qual defendia a utilização de Educação e Propagandas Sanitárias e explicitava os melhores métodos, conforme os pressupostos da Fundação Rockefeller. Afirmava que educação e propaganda sanitárias estavam conseguindo o que não fora possível com legislação e administração entre os norte-americanos. Folhetos de propaganda, conferências e demonstrações práticas sobre medidas higiênicas eram acolhidas pela população com interesse e atenção (Barros Barreto, 1923a, p. 1038).

Barros Barreto apontava que Oswaldo Cruz teve o mérito de ser o primeiro a introduzir os processos de educação sanitária entre os brasileiros, pois ordenou, em suas campanhas higiênicas, a distribuição de folhetos que denunciavam o perigo relacionado a certas doenças. Ao iniciar os trabalhos de profilaxia da ancilostomíase no Brasil, a Comissão Rockefeller teria trazido os processos mais modernos de propaganda sanitária, colhendo de sua aplicação os melhores proveitos. Por fim, enfatizava o êxito na distribuição de publicações e realização de conferências pela Profilaxia Rural do DNSP (Barros Barreto, 1923a, p. 1041).

Educação e Propaganda Sanitárias se transformaram em um dos principais instrumentos utilizados para tentar convencer a população baiana sobre a profilaxia, com a adoção de hábitos higiênicos. Elas passaram a ser vistas como temáticas de Higiene mais complexas do que aparentavam e, para o médico, os resultados mais positivos estiveram sempre em programas que não davam preferência a apenas um instrumento educacional, já que um método poderia corrigir as lacunas e completar os outros. Elencava-se, portanto, a necessidade de utilizar métodos que empregassem a palavra falada e escrita, bem como a importância de recorrer à imprensa visual e aos chamados processos mistos (conferências acompanhadas de projeções) (Barros Barreto, 1923b, p. 1103; Batista, 2019b).

A promoção desse ideal estava sob a responsabilidade da Diretoria de Demografia e Educação Sanitária da Bahia, que também se encarregava da organização da estatística demógrafo-sanitária de todos os municípios do estado; da realização, em estreita colaboração com os centros de saúde, do cadastro e recenseamento quinquenal dos prédios e da população da capital e do seu município; da instalação da seção de estatística do museu de higiene, na qual figuravam mapas epidemiológicos, cartogramas e representações esferográficas, e do movimento demográfico-sanitário de Salvador e diversos municípios baianos. Além disso, cabia a esse setor a instrução da população de diferentes municípios sobre o modo de contrair doenças, nos métodos 
considerados como mais eficazes e modernos de evitá-las e no perigo da inobservância das regras de "boa saúde" (Barros Barreto, 1928, p. 33-34).

De acordo com os pressupostos de Educação e Propaganda Sanitárias, um conjunto de 33 cartazes foi elaborado pela Secretaria de Saúde e Assistência Pública, com figuras que objetivavam disseminar hábitos saudáveis, cuidados com a infância, com a higiene industrial e com as endemias rurais, entre outros, para serem distribuídos e utilizados em postos e centros de saúde do estado (Figura 2).

Figura 2 - Cartazes de Educação e Propaganda Sanitárias.
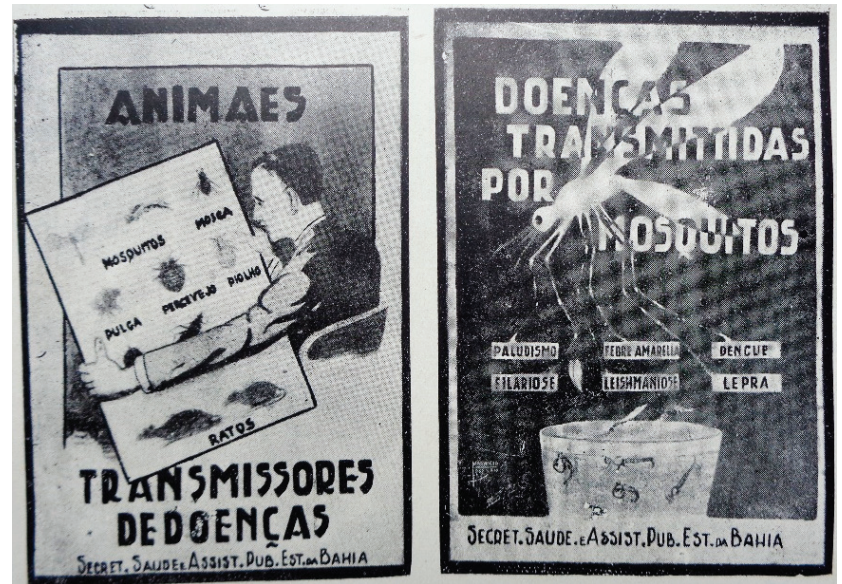

Fonte: Barros Barreto, 1928.

A criação dos centros de saúde, em Salvador, esteve relacionada à trajetória das Delegacias de Saúde. Segundo Santos (2018, p. 47), o surgimento destas últimas não atendia apenas a uma deliberação estadual, mas seguia o modelo federal de Reforma Sanitária, visto que, junto à criação do DNSP, haviam sido instituídas dez delegacias de saúde, cujo objetivo estava voltado para a profilaxia. No processo de transformação da Subsecretaria de Saúde e Assistência Pública para o status de Secretaria, em 1927, o médico extinguiria as delegacias, passando a denominá-las como centros de saúde, mesmo que continuassem sendo referidas com o nome anterior, em um processo de transição que se iniciou em 1928 e foi até 1930 (Santos, 2018, p. 61).

Em 1927 funcionavam dois centros. O primeiro, no bairro da Calçada, localizado no subúrbio de Salvador, e o segundo em Monst'Serrat. Além das atribuições destinadas às delegacias (combate a doenças transmissíveis, polícia 
sanitária, verificação de óbitos), os Centros de Saúde criados em Salvador possuíam dispensários de profilaxia das helmintoses, paludismo, sífilis e doenças venéreas, tuberculose, higiene infantil e maternal, higiene mental, clínica dentária e otorrino-oftalmolaringológica, e dispunham de laboratório para exames bacteriológicos e pesquisas outras necessárias à elucidação do diagnóstico e ao regular funcionamento das diversas dependências do centro (Barros Barreto, 1928, p. 34).

A adoção dos centros de saúde se configura como uma influência norte-americana, a partir da inserção da Fundação Rockefeller no país e da atuação de Barros Barreto na Bahia. Essas instituições se mostraram diferentes no Brasil e nos Estados Unidos, mas tinham como característica comum a educação sanitária. Entre os centros de saúde brasileiros, as unidades sanitárias foram inauguradas e operadas a partir da cooperação da instituição norte-americana com os governos estaduais, como ocorreu em São Paulo (Castro Santos; Faria, 2010, p. 156-158). O objetivo era definir uma delimitação territorial com o intuito de, nela, fiscalizar, educar e implementar medidas profiláticas relativas à higiene, de modo que a população pudesse cuidar de todos os seus interesses num único local.

Ainda em relação às ações desenvolvidas pelos profissionais da saúde no contexto da Reforma Sanitária da Bahia, é possível elencar as atividades do IOC-Ba, os Serviços de Profilaxia da Tuberculose (Silva, 2018), Sífilis e Doenças Venéreas (Batista 2017a; 2017b; 2016), os Postos Municipais de Higiene (que executavam trabalhos de educação, propaganda sanitária, endemias rurais, doenças venéreas, lepra, tuberculose, doenças epidêmicas, estatísticas, inspeção do leite e carne, higiene maternal, infantil, escolar, polícia sanitária e higiene industrial, obrigando-se o município a destinar para esse fim 5\% da receita orçada em cada exercício). Entretanto, em alguns municípios do interior era difícil fazer os intendentes contribuírem com a cota definida, como ocorreu, em 1927, na cidade de Esplanada (Batista, 2017b, p. 219-220).

O Serviço de Luta Contra Animais Transmissores era efetivado especialmente na luta contra insetos, com o auxílio da Fundação Rockefeller, executado pelos guardas sanitários dos centros de saúde em colaboração com o pessoal do desinfetório, que era incumbido dos expurgos e desinfecções (Barros Barreto, 1928, p. 35-38), mas em muitos momentos as ações sanitárias não atingiam as expectativas das elites médicas. Pontes (2007, cap. 3), por exemplo, mostra como a população pobre de Salvador reagia à intervenção da Fundação Rockefeller em suas casas e em seus hábitos. 
Diretrizes similares às observadas na Reforma dirigida por Barros Barreto a partir de 1925 podem ser identificadas na experiência de Fernando de Freitas e Castro, no Rio Grande do Sul, em 1929, o que se pode atribuir à formação de ambos, realizada no exterior. O médico, que foi para a Johns Hopkins University no ano em que Barros Barreto deixou os Estados Unidos rumo à Europa, desenvolveu um projeto de reorganização sanitária no seu estado, enquanto Diretor de Higiene. Freitas e Castro defendia com veemência uma reforma dos serviços de higiene e saúde pública e, também, a elaboração de um novo Código Sanitário. Além disso, considerava necessário preparar o pessoal técnico para trabalhar nos diferentes serviços da Repartição (Korndörfer, 2013, p. 248, 253). Diferentemente da Bahia, que pôde enviar o seu pessoal para outros estados e para o exterior, Freitas e Castro afirmava não ser possível contar com os cursos existentes na Capital Federal e no estrangeiro, o que resultou na criação do Curso de Higiene e Saúde Pública do Rio Grande do Sul.

\section{CONSIDERAÇÕES FINAIS}

A análise das ações de Antônio Luis Cavalcanti de Albuquerque de Barros Barreto na Reforma Sanitária na Bahia contribui para compreender como o estado se inseriu na expansão do aparato sanitário do Brasil pós-1920, que ocorreu, entre outros aspectos, com o auxílio de ex-bolsistas da Fundação Rockefeller, como afirmam Castro Santos e Faria (2003) e Körndofer (2013).

A maior parte da documentação utilizada para este estudo foi produzida pelo próprio Barros Barreto com o intuito de publicizar o seu trabalho, o que exige uma compreensão das informações, situando-as nos contextos possíveis para a atuação do médico, que envolveram aspectos como aspirações profissionais e pessoais, além da percepção sobre as diretrizes mais amplas do projeto sanitário que ele procurou empreender. O registro sistemático desse processo, presente nos relatórios da Subsecretaria de Saúde e Assistência Pública, também integra uma forma específica de documentar à luz da metodologia da Fundação Rockefeller, o que demonstra mais uma vez a intensidade do vínculo estabelecido entre o médico e a Instituição.

As ações sanitárias realizadas sob a orientação de Barros Barreto foram marcadas pela centralização proposta pelo DNSP, fruto do movimento sanitarista da década de 1910, que foi operacionalizada pelos acordos firmados com os estados. Isso possibilitou que a Bahia implementasse políticas de profilaxia rural, higiene infantil e combate à sífilis, à lepra e à tuberculose, por exemplo, a partir de diretrizes nacionais. Ao mesmo tempo, esse processo foi 
desenvolvido com orientação técnica adquirida no exterior e priorizou o investimento na capacitação dos funcionários da Bahia em outros estados e países e a inserção de profissionais de fora entre os baianos, além de seguir métodos de educação e propaganda sanitária orientados e utilizados pela instituição filantrópica norte-americana no Brasil e em outros lugares do mundo.

Muitas das políticas empreendidas nesse projeto lograram êxito, especialmente se observadas como uma ampliação dos braços do Estado sobre as unidades federativas, com a criação de estruturas voltadas para o enfrentamento de doenças num país que contava, até então, com ações estatais apenas em momentos de calamidade pública. A assistência à saúde era realizada, essencialmente, pelas Santas Casas de Misericórdia, instituições filantrópicas e de auxílio mútuo. No entanto, estiveram distantes de dar conta dos problemas sanitários e de saúde que acometiam a população de modo geral e, principalmente, os pobres.

Visibilizar um momento específico da trajetória de Barros Barreto auxilia na compreensão de como confrontos políticos e disputas médicas entre as elites econômicas também se relacionavam ao campo da saúde. Em meio a esses conflitos, o médico objetivava colocar o sanitarismo em prática, o que se deu, em grande medida, pela difusão da educação e propaganda sanitárias e pela formação técnica de médicos e enfermeiras que desempenhariam funções na capital e nos Postos de Saneamento Rural. Esses profissionais também foram enviados para áreas em que não havia postos, com o objetivo de conhecer as condições sanitárias de muitos municípios e combater endemias e epidemias.

\section{FONTES}

BAHIA. Lei no 1.811, de 29 de julho de 1925. Organiza a Subsecretaria de Saúde e Assistência Pública. Diário Oficial do Estado da Bahia, Poder Legislativo. Bahia, 1925.

BARROS BARRETO, Antônio Luis Cavalcanti de Albuquerque de. Discurso de posse na Sub-secretaria de Saúde e Assistência Pública. Salvador: Academia de Letras na Bahia (ALB), 1925.

BARROS BARRETO, Antônio Luis Cavalcanti de Albuquerque de. Educação e propaganda sanitarias: importancia na defesa da saude collectiva. Boletim sanitário do Departamento Nacional de Saúde Pública, v. 2, n. 5, ago. 1923. Archivos Brasileiros de Medicina, v. 13, n. 11, nov. 1923a.

BARROS BARRETO, Antônio Luis Cavalcanti de Albuquerque de. Methodos de propaganda sanitaria. Boletim sanitário do Departamento Nacional de Saúde Pública, v. 2, n. 5, p. 39, ago. Archivos Brasileiros de Medicina, v. 13, n.11, p. 1103, nov. 1923 b. 
BARROS BARRETO, Antônio Luis Cavalcanti de Albuquerque de. Relatorio apresentado ao Snr. Dr. Director pelo Dr. Antônio Luiz C. A. Barros Barreto (chefe do serviço). Archivos Paranaenses de Medicina, v. 5, n. 4, p. 111-121, ago./set. 1924.

BARROS BARRETO, Antônio Luis Cavalcanti de Albuquerque de. Relatório da Secretaria de Saúde e Assistência Pública: anno de 1927. Bahia: Imprensa Oficial do Estado, 1928.

BARROS BARRETO, Antônio Luis Cavalcanti de Albuquerque de. Revisão da subfamília SUBULURINAE Travassos, 1914. Dissertação (Tese de Medicina - Cadeira de História Natural) - Faculdade de Medicina do Rio de Janeiro. Rio de Janeiro: Tipografia Leuzinger, 1918.

BARROS BARRETO, Antônio Luis Cavalcanti de Albuquerque de. Seis Annos de Administração Sanitária. Rio de Janeiro: Typografia do Jornal do Commercio, 1931.

BARROS BARRETO, Antônio Luis Cavalcanti de Albuquerque de. Titulos e trabalhos científicos: memorial apresentado á Faculdade de Medicina da Bahia, ao concorrer a vaga de Professor Cathedrático de PARASITOLOGIA. Bahia: Imprensa Official do Estado, 1935.

RAC (ROCKEFELLER ARCHIVE CENTER), series MNS, record group 10.2 (Fellowship Recorder Cards, Barros Barreto).

RAC (ROCKEFELLER ARCHIVE CENTER), series MNS, record group 10.2 (Fellowship Recorder Cards, Torres).

TORRES, Octávio. Relatório dos trabalhos executados no Laboratório de Prophylaxia da Diretoria de Saneamento Rural apresentado pelo Dr. Octavio Torres. Arquivo Público do Estado da Bahia. Caixa 4082, maço 114, 1927.

\section{REFERÊNCIAS}

BATISTA, Ricardo dos Santos. Educação e propaganda sanitárias: desdobramentos da formação de um sanitarista brasileiro na Fundação Rockefeller. História, Ciências, Saúde - Manguinhos, Rio de Janeiro, v. 26, n. 4, out./dez. 2019b.

BATISTA, Ricardo dos Santos. A formação inicial de Antônio Luis Cavalcanti de Albuquerque de Barros Barreto: uma trajetória rumo à saúde internacional. História, Ciências, Saúde - Manguinhos, Rio de Janeiro, v. 26, n. 3, p. 801-822, jul./set. 2019a.

BATISTA, Ricardo dos Santos. Um projeto de combate à sífilis na Bahia. Intellèctus, Rio de Janeiro: Uerj, v. 15, n. 2, 2016.

BATISTA, Ricardo dos Santos. Sífilis e reforma da saúde na Bahia (1920-1945). Salvador: Eduneb, 2017a.

BATISTA, Ricardo dos Santos. Sífilis e relações de gênero na Bahia. In: FRANCO, Sebastião Pimentel; NASCIMENTO, Dilene Raimundo do; SILVEIRA, Anny 
Jacqueline Torres (org.). Uma História Brasileira das doenças. v. 7. Belo Horizonte: Fino Traço, 2017b. p. 113-132.

BENCHIMOL, Jaime Larry (coord.). Febre amarela: a doença e a vacina, uma história inacabada. Rio de Janeiro: Ed. Fiocruz, 2001.

BOURDIEU, Pierre. O campo científico. In: ORTIZ, Renato (org.). Pierre Bourdieu: sociologia. São Paulo: Ática, 1983.

BOURDIEU, Pierre. A ilusão biográfica. In: AMADO, Janaína; FERREIRA, Marieta de M. Usos e abusos da história oral. 8. ed. Rio de Janeiro: Ed. FGV, 2006. p. 183-191.

CAMPOS, Cristina de. A viagem de Geraldo Paula Souza para os Estados Unidos, 1918-1920: fragmentos de uma história da relação entre a Fundação Rockefeller e o Instituto de Higiene de São Paulo. In: MARINHO, Maria Gabriela da S. M. da C.; MOTA, André (org.). Caminhos e trajetos da filantropia científica em São Paulo: a Fundação Rockefeller e suas articulações no Ensino, Pesquisa e Assistência para a Medicina e Saúde (1916-1952). São Paulo: USP/Faculdade de Medicina: Universidade Federal do ABC: CD.G Casa de Soluções e Editora, 2013. p. 37-56.

CASTRO SANTOS, Luiz Antônio de; FARIA, Lina Rodrigues. O ensino de saúde pública no Brasil: os primeiros tempos no Rio de Janeiro. Trabalho, educação e saúde, Rio de Janeiro, v. 4, n. 2, 2006.

CASTRO SANTOS, Luiz Antônio de; FARIA, Lina. Os primeiros Centros de Saúde nos Estados Unidos e no Brasil: um estudo comparativo. In: CASTRO SANTOS, Luiz Antônio de; FARIA, Lina. Saúde \& História. São Paulo: Aderaldo \& Rothschild, 2010. p. 154-186.

CASTRO SANTOS, Luiz Antônio de; FARIA, Lina Rodrigues. A reforma sanitária no Brasil: ecos da Primeira República. Bragança Paulista: Edusf, 2003.

CUETO, Marcos (ed.). Missionaries of Science: The Rockefeller Foundation and Latin America. Bloomington, IN: Indiana University Press, 1994.

EDLER, Flávio. A medicina no Brasil Imperial: climas, parasitas e patologia tropical. Rio de Janeiro: Ed. Fiocruz, 2011.

FARIA, Lina. Educadoras sanitárias e enfermeiras de saúde Pública: identidades profissionais em construção. Cadernos Pagu, São Paulo, v. 27, n. 1, 2006.

FERREIRA, Luiz Otávio. João Vicente Torres Homem: descrição da carreira médica no século XIX. Physis - Revista de Saúde Coletiva, Rio de Janeiro: IMS-Uerj, v. 4, n. 1, 1994.

HOCHMAN, Gilberto. Logo ali, no final da avenida: os sertões redefinidos pelo movimento sanitarista da Primeira República. História, Ciências, Saúde - Manguinhos, Rio de Janeiro, v. 5, supl. 1998.

HOCHMAN, Gilberto. Regulando os efeitos da interdependência: sobre as relações entre saúde pública e construção do Estado (Brasil 1910-1930). Estudos Históricos, Rio de Janeiro, v. 6, n. 11, 1993. 
HOCHMAN, Gilberto; LIMA, Nísia Trindade. Médicos intérpretes do Brasil. São Paulo: Hucitec, 2015.

KORNDÖRFER, Ana Paula. "An international problem of serious proportions": a cooperação entre a fundação Rockefeller e o Governo do Estado do Rio Grande do Sul no Combate à ancilostomíase e seus desdobramentos (1919-1929). 2013. Tese (Doutorado em História) - Pontifícia Universidade Católica do Rio Grande do Sul (PUC-RS). Porto Alegre, 2013.

LIMA, Nísia Trindade; HOCHMAN, Gilberto. Condenado pela raça, absolvido pela medicina: o Brasil descoberto pelo movimento sanitarista da Primeira República. In: MAIO, Marcos Chor; SANTOS, Ricardo Ventura (org.). Raça, ciência e sociedade. Rio de Janeiro, Ed. Fiocruz, 1996.

LÖWY, Ilana. Virus, mosquitos e modernidade: a febre amarela no Brasil entre ciência e política. Rio de Janeiro: Ed. Fiocruz, 2006.

MAIO, Marcos Chor. A medicina de Nina Rodrigues: análise de uma trajetória científica. Cadernos de Saúde Pública, Rio de Janeiro, v. 11, n. 2, p. 226-237, abr./jun. 1995.

MOREIRA, Martha Cristina N. A Fundação Rockefeller e a construção da identidade profissional de enfermagem no Brasil na Primeira República. História, Ciências, Saúde - Manguinhos, Rio de Janeiro, v. 5, n. 3, 1999.

PAIVA, Carlos Henrique A. Samuel Pessoa: uma trajetória científica no contexto do sanitarismo campanhista e desenvolvimentista no Brasil. História, Ciências, Saúde - Manguinhos, Rio de Janeiro, v. 13, n. 4, p. 794-831, out./dez. 2006.

PALMER, Steven. Gênese da Saúde Global: a Fundação Rockefeller no Caribe e na América Latina. Rio de Janeiro: Ed. Fiocruz, 2015.

PONTES, Adriano Arruda. Caçando mosquitos na Bahia: a Rockefeller e o combate à febre amarela - inserção, ação e reação popular (1918-1940). 2007. Dissertação (Mestrado em História) - Universidade Federal da Bahia (UFBA). Salvador, 2007. SANTOS, Chacauana Araújo dos. "Medidas sanitárias de que a Bahia precisa": as Delegacias de Saúde, o Hospital de Isolamento e a Reforma Sanitária em Salvador (1921-1930). 2018. Dissertação (Mestrado em História) - Universidade do Estado da Bahia (Uneb). Alagoinhas, 2018.

SCHMIDT, Benito Bisso. Em busca da terra da promissão: a história de dois líderes socialistas. Porto Alegre: Palmarinca, 2004.

SCHMIDT, Benito Bisso (org.). O biográfico: perspectivas interdisciplinares. Santa Cruz do Sul: Edunisc, 2000.

SILVA, André Felipe C. da. Um brasileiro no Reich de Guilherme II: Henrique da Rocha Lima, as relações Brasil-Alemanha e o Instituto Oswaldo Cruz. História, Ciências, Saúde - Manguinhos, Rio de Janeiro, v. 20, n. 1, p. 93-117, jan./mar. 2013. 
SILVA, Maria Elisa L. N. da. Ciência e saúde no "centro" do Brasil: a trajetória do médico José Silveira na luta contra a tuberculose. In: SILVA, Maria Elisa L. N. da. Rastros biográficos: estudos de trajetórias. Salvador: Eduneb, 2014.

SILVA, Maria Elisa L. N. da. O Dispensário Ramiro de Azevedo e a constituição de políticas de enfrentamento da tuberculose na Bahia na década de 1920. In: SILVA, Maria Elisa L. N. da; BATISTA, Ricardo dos Santos (org.). História e Saúde: políticas, assistência, doenças e instituições na Bahia. Salvador: Eduneb, 2018.

SOUZA, Christiane Maria C. de. A gripe espanhola na Bahia: saúde, política e medicina em tempos de epidemia. Rio de Janeiro: Ed. Fiocruz; Salvador: Edufba, 2009.

\section{NOTAS}

${ }^{1}$ Esta pesquisa recebeu o apoio do Edital Universal 2018, do Conselho Nacional de Desenvolvimento Científico e Tecnológico (CNPq), processo 428804/2018-7.

${ }^{2}$ Entre 1934 e 1937 Barros Barreto ocupou o cargo de Secretário de Educação e Saúde no estado, mas esse período não será abordado aqui.

${ }^{3}$ Para mais informações sobre o movimento sanitarista, cf. Hochman (1993; 1998).

${ }^{4}$ Barros Barreto tornou-se genro de Góes Calmon, o que estreitou ainda mais a sua relação com o então governador.

${ }^{5}$ Flávio Edler questiona a divisão entre uma medicina pré-científica e uma medicina "científica" que teria surgido com o advento da microbiologia. Para o autor, as bases da medicina realizada com o auxílio do microscópio estiveram no modelo anterior, em um processo de continuidade e não de abrupta cisão (cf. EDLER, 2011).

Artigo recebido em 15 de maio de 2019. Aprovado em 23 de janeiro de 2020. 